\title{
BDNF contributes to the skeletal muscle anti-atrophic effect of exercise training through AMPK-PGC1 $\alpha$ signaling in heart failure mice
}

\author{
Zheng Zhang ${ }^{1}$, Beili Wang ${ }^{2}$, Aihua Fei ${ }^{1}$
}

\author{
${ }^{1}$ Department of Emergency, Xin Hua Hospital affiliated to Shanghai JiaoTong \\ University School of Medicine, Shanghai, China \\ ${ }^{2}$ Department of Oncology, Xin Hua Hospital affiliated to Shanghai JiaoTong University \\ School of Medicine, Shanghai, China
}

Submitted: 5 September 2017

Accepted: 4 December 2017

Arch Med Sci 2019; 15, 1: 214-222

DOI: https://doi.org/10.5114/aoms.2018.81037

Copyright (c) 2018 Termedia \& Banach

\section{Abstract}

Introduction: Exercise training is a coadjuvant therapy in preventive cardiology, and it delays cardiac dysfunction and exercise intolerance in heart failure (HF). However, the mechanisms underlying muscle function improvement and cardioprotection are poorly understood. In this study, we tested whether exercise training would counteract skeletal muscle atrophy via activation of the BDNF pathway in myocardial infarction (MI)-induced HF mice. Material and methods: A cohort of male Sham-operated and MI mice were assigned into 8-week moderate exercise training, and untrained counterparters were used as control. Exercise capacity, plasma norepinephrine (NE) level, heart rate (HR), fractional shortening (FS) and ejection fraction (EF) were measured. The protein expression of BDNF, p-TrkB, p-AMPK and PGC1 $\alpha$ were analyzed by Western blot.

Results: Compared with the Sham-operated mice, MI mice displayed reduced total distance run and elevated plasma NE level (both $p<0.05$ ). Exercise training significantly improved distance run and plasma NE levels in $\mathrm{HF}$ mice (both $p<0.05$ ). Significantly increased HR, decreased FS and EF were observed in the $\mathrm{MI}$ group as compared to the Sham-operated group, and exercise training prevent the hemodynamic status and systolic dysfunction in MI mice (all $p<0.05$ ). The expression of BDNF, $\mathrm{p}-$ TrkB, $\mathrm{p}-\mathrm{AMPK}$ and PGC1 $\alpha$ were significantly decreased in the skeletal muscle from $\mathrm{MI}$ compared to Sham-operated mice, which were significantly increased by exercise training (all $p<0.05$ ). In addition, BDNF siRNA markedly decreased the protein level of p-AMPK and PGC1 $\alpha$ in C2C12 myoblasts.

Conclusions: Taken together, our data provide evidence for exercise training may counteract HF-induced muscle atrophy through induced activation of BDNF pathway.

Key words: heart failure, skeletal muscle, ventricular function, exercise training, BDNF/TrkB, AMPK/PGC1 $\alpha$.

\section{Introduction}

Exercise training is effective in reducing cardiovascular disease risk factors [1, 2], and it is also an important strategy for the prevention and treatment of cardiovascular diseases $[3,4]$. Heart failure (HF) is a complex clinical syndrome representing the end stage of a number of

\author{
Corresponding author: \\ Aihua Fei \\ Department of Emergency \\ Xin Hua Hospital \\ affiliated to Shanghai \\ JiaoTong University \\ School of Medicine \\ 1665, Kongjiang Road \\ Shanghai 200092, China \\ Phone: 13621807753 \\ E-mail: feiaihua@xinhuamed. \\ com.cn
}


different cardiac diseases. One of the major clinical manifestations of $\mathrm{HF}$ is exercise intolerance, which is closely related to poor prognosis in HF patients [5-7]. In HF, exercise training improves patient outcome by increasing exercise tolerance $[8,9]$ and reducing dyspnea and fatigue [10]. However, its mechanism in HF has not been elucidated.

Brain-derived neurotrophic factor (BDNF), a member of the neurotrophic factor family, has been demonstrated to regulate various neuronal functions including neuroregeneration, neuroprotection, synapse development and plasticity [11]. BDNF is essential for heart development because its genetic deletion leads to the thinning of cardiac chambers, microvascular leakage and, ultimately, early death in mice [12]. In adult mammals, BDNF modulates autonomic transmission to the heart [13] and exerts prominent angiogenic effects [14]. Recent evidence also points to the presence of its receptor, tyrosine receptor kinase $B$ (TrkB), in the myocardium $[15,16]$. Serum BDNF levels are decreased and correlated with exercise capacity in HF patients, and have been shown to be increased by exercise training $[17,18]$. However, the role of myocardial BDNF/TrkB signaling in cardiac physiology and myocardial response to exercise training, is largely unknown.

Considering that BDNF through AMPK/PGC-1 $\alpha$ triggers mitochondrial function of skeletal muscle and exercise training increases BDNF levels in HF patients [19], we hypothesized that activation of the BDNF/TrkB and AMPK/PGC-1 $\alpha$ pathway would be involved in exercise training preventing HF induced muscle dysfunction in mice.

\section{Material and methods}

\section{Ethics statement}

Animal studies were approved by the Ethical Committee of Ethics in Animal Research of the Xin Hua hospital and were conducted in accordance with the International Guiding Principles for Biomedical Research Involving Animals as promulgated by the Society for the Study of Reproduction.

\section{Animals}

Eight-week-old male C57BL/6J mice weighing 22-25 g were obtained from Shanghai SLAC Laboratory Animal Company. Mice were housed in a 12 : $12 \mathrm{~h}$ dark-light cycle and temperature-controlled environment $\left(22^{\circ} \mathrm{C}\right)$ with free access to standard laboratory chow and water. Mice were acclimated for 7 days before any experimental procedures.

\section{Cell culture}

C2C12 cells (ATCC, Manassas, VA) were maintained in growth medium consisting of Dulbecco's modified Eagle's medium (DMEM) supplemented with $10 \%$ fetal bovine serum (Gibco, USA). Cells were cultured in a humidified incubator under an atmosphere of $5 \% \mathrm{CO}_{2}$ at $37^{\circ} \mathrm{C}$. Differentiation of myoblasts into myotubes was induced by switching to differentiation medium consisting of DMEM supplemented with $2 \%$ horse serum (Gibco, USA) when cells reached 90 to $95 \%$ confluency. Myotubes were used for experiments following 4 days of differentiation.

\section{SiRNA transfection}

Control and BDNF mRNA-specific siRNAs were obtained from Genepharm Company (Shanghai). C2C12 cells cultured in growth medium in 24-well plates were transfected with siRNAs $(1 \mu \mathrm{g}$ per well) using Lipofectamine RNAiMAX reagent (Invitrogen, Carlsbad, Calif, USA). Forty-eight hours after transfection, cells were switched to differentiation medium and cultured for $96 \mathrm{~h}$ or otherwise indicated.

\section{Experimental design}

Forty mice were assigned to four groups: untrained CON (CON-UT, 10), exercise-trained CON (CON-T, 10), untrained HF (HF-UT, 10) and exercise-trained HF (HF-T, 10). Mice were intubated and were under mechanical ventilation with adequate anesthesia by pentobarbital $(50 \mathrm{mg} / \mathrm{kg}$, intraperitoneally). Then, myocardial infarction (MI) was created by ligation of the left coronary artery, as described previously [20]. Excluding the suturing of the coronary artery, the same surgical procedure was performed, and the sham-operated mice were used as the control group. Sham-operated and $\mathrm{MI}$ mice were randomly assigned to untrained and exercise-trained groups.

\section{Exercise training protocol}

At 4 weeks after $\mathrm{Ml}$ induction, mice were submitted to moderate-intensity exercise training in swimming warmed-water $\left(30-32^{\circ} \mathrm{C}\right)$ apparatus for $60 \mathrm{~min}, 5$ days/week for 8 weeks [21]. The training sessions were performed during the dark cycle of the mice. All untrained mice were placed in the swimming apparatus for 5 min three times a week to become accustomed to the exercise protocol and handling.

\section{Graded treadmill exercise test}

Exercise capacity, estimated by total distance run, was evaluated using a graded treadmill exercise protocol for mice as previously described [22]. Briefly, after being adapted to treadmill exercises over 1 week (10 min/day), mice were placed on the treadmill lane and allowed to ac- 
climatize for at least $30 \mathrm{~min}$. Treadmill speed started at $6 \mathrm{~m} / \mathrm{min}$ and increased by $3 \mathrm{~m} / \mathrm{min}$ every 3 min with no grade until exhaustion. Tests were performed in sham-operated and $\mathrm{MI}$ mice by a blinded observer. Total distance run (meters) was recorded.

\section{Cardiovascular measurements}

Heart rate (HR) was determined non-invasively using a computerized tail-cuff system (BP 2000 Visitech Systems, Apex, USA) [21]. Mice were acclimatized to the apparatus during daily sessions over 6 days, 1 week before starting the experimental period. Heart rate measurements were obtained serially in sham-operated and $\mathrm{MI}$ mice once a week throughout the 8 weeks of the experiment.

\section{Echocardiographic assessment}

Cardiac function was assessed by two-dimensional guided M-mode echocardiography in halothane-anesthetized sham-operated and MI mice. Mice were positioned in the supine position with front paws wide open and an ultrasound transmission gel was applied to the precordium. Echocardiography was performed using an Acuson Sequoia model 512 echocardiography machine (Acuson Corporation, Mountain View, CA, USA) equipped with a $14-\mathrm{MHz}$ linear transducer. Ventricular structure and systolic function were measured as we previously described [23]. Parameters included left ventricular end-diastolic and end-systolic dimensions (LVEDD and LVESD), left ventricular ejection fraction (LVEF) and fractional shortening (LVFS). Heart failure was defined based on the in vivo LV dysfunction (LVEF, $40 \%$ in this study).

A

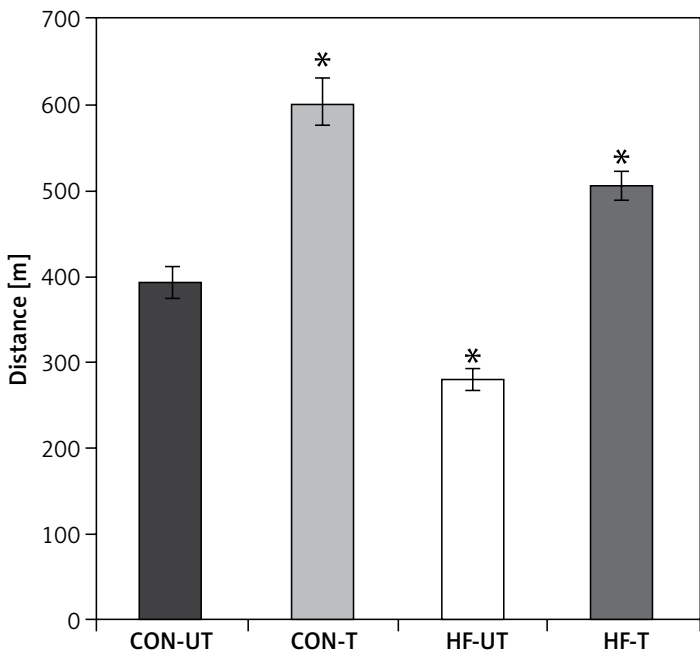

\section{Plasma norepinephrine levels}

Plasma norepinephrine was measured by HPLC using ion-pair reverse-phase chromatography coupled with electrochemical detection $(0.5 \mathrm{~V})$ as described by Medeiros et al. [24].

\section{Western blot}

Soleus muscle samples were harvested and homogenized on ice in RIPA lysis buffer (Beyotime, Jiangsu, China). Lysates were centrifuged at 12,000 $\times \mathrm{g}$ for $20 \mathrm{~min}$ at $4^{\circ} \mathrm{C}$. The protein concentrations were measured using a BCA kit (Pierce Chemical, Rockford, IL, USA). Equivalent amounts of protein extracts $(50 \mu \mathrm{g})$ were separated by $10 \%$ SDS-polyacrylamide gel electrophoresis and transferred onto PVDF membranes (Millipore Corp., Billerica, MA, USA). The membranes were blocked for $1 \mathrm{~h}$ with $5 \%$ non-fat dry milk in Tris-buffered saline/ Tween-20 (TBST) buffer, and then incubated with primary antibodies against BDNF, $p$-TrkB, p-AMPK and PGC1 $\alpha$ (1: 1000 dilution) (Cell Signaling Technology, Inc., Danvers, MA) at $4^{\circ} \mathrm{C}$ overnight. Blots were washed three times and incubated with corresponding secondary antibodies for $1 \mathrm{~h}$ at room temperature. The signals were developed using enhanced chemiluminescence $(\mathrm{ECL})$ reagent (Tiangen Biotech Co., Ltd., Beijing, China) and visualized with Quantity One software. Targeted bands were normalized to cardiac GAPDH.

\section{RT-PCR}

Total RNA was extracted from soleus muscles in each group using Trizol reagent (Invitrogen, Carlsbad, CA, USA). RNA purity was estimated by cal-

\section{B}

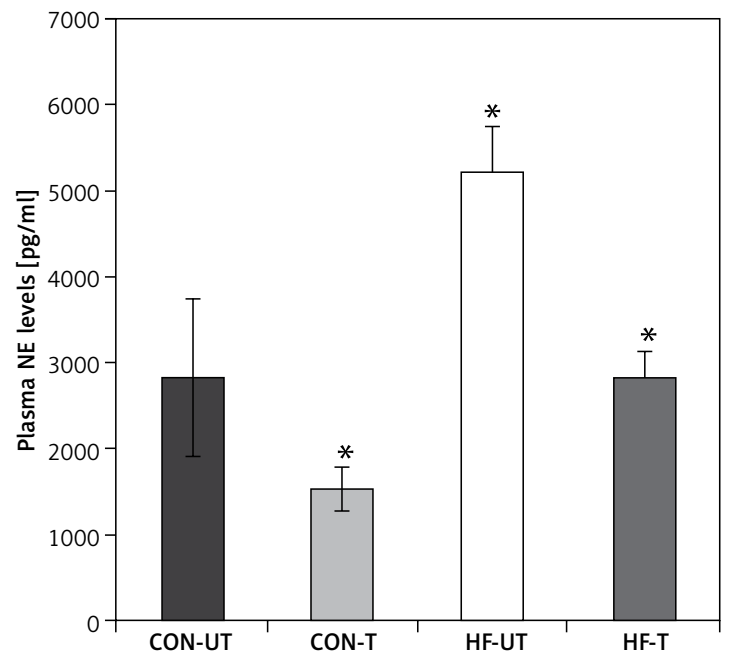

Figure 1. Distance run (A) and plasma norepinephrine (NE) levels (B) in untrained and exercise-trained sham-operated mice (CON-UT and CON-T, respectively), and untrained and exercise-trained MI mice (HF-UT and HF-T, respectively). Note that exercise training significantly improved distance run in $\mathrm{HF}$ mice

Data are presented as means $\pm S E .{ }^{*} P<0.05 \mathrm{vs}$. CON-UT group 


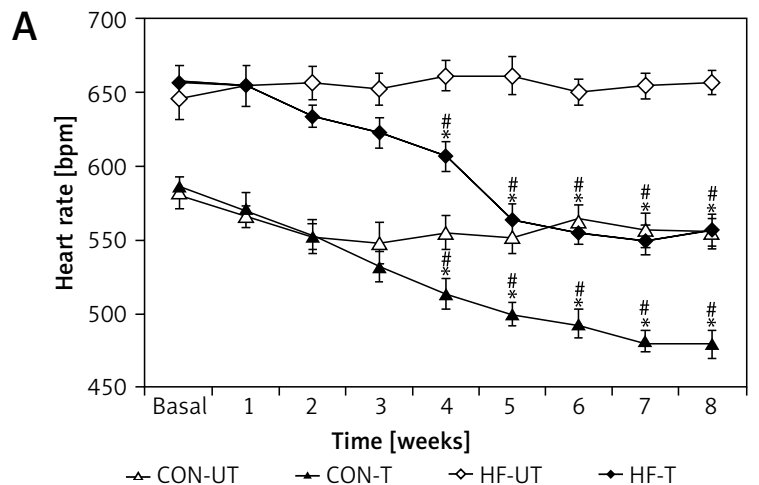

B

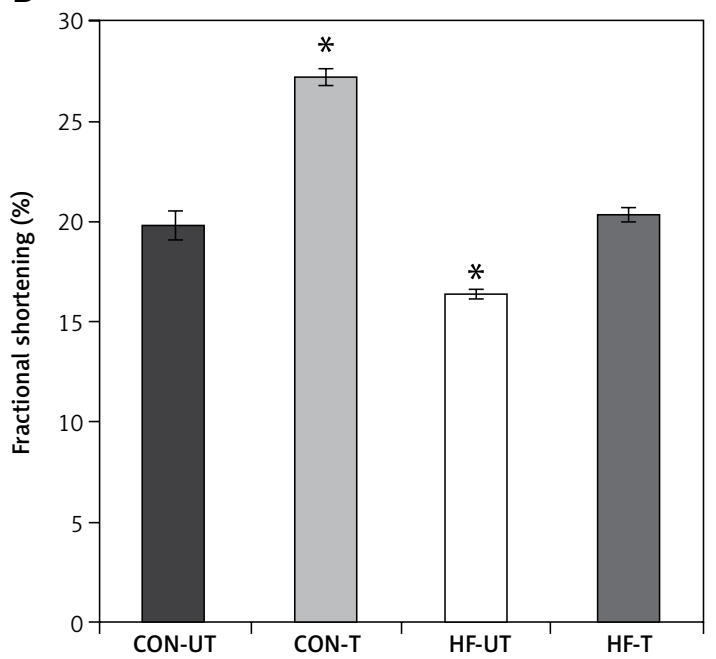

C

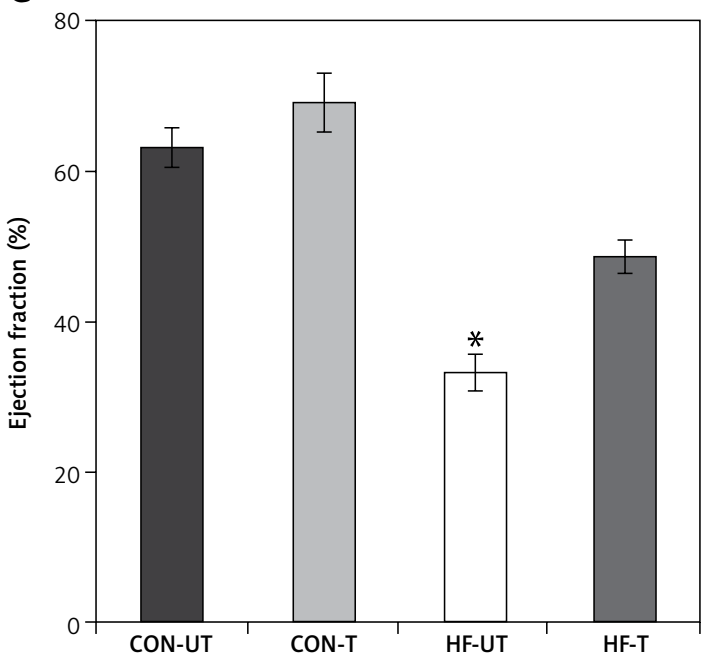

Figure 2. Heart rate (A), fractional shortening (B) and ejection fraction (C) in untrained and exercise-trained shamoperated mice (CON-UT and CON-T, respectively), and untrained and exercise-trained MI mice (HF-UT and HF-T, respectively). Note that exercise training decreased HR, and increased FS and EF levels in HF mice toward those of untrained CON mice

Data are presented as means $\pm S E .{ }^{*} P<0.05$ vs. basal levels; ${ }^{*} p<0.05$ vs. untrained group.

culating the 260/280 $\mathrm{nm}$ absorbance and reverse transcribed into cDNA using Transcript First-strand cDNA Synthesis SuperMix (TransGen Biotech, Beijing, China) in accordance with the manufacturer's protocol. RT-PCR was performed using a Super Real PreMix Plus (SYBR Green) kit (Tiangen, Beijing, China) with BDNF gene sets or GAPDH primers. The reactions were performed three times using an $A B I$ Prism 7500 Sequence Detection System ( $\mathrm{ABI}$, Foster City, CA, USA). All data from each sample were assessed by $2^{-\Delta \Delta C t}$ analysis.

\section{Statistical analysis}

All values are presented as means \pm standard error (SE). Data were tested for normal distribution and one-way analysis of variance (ANOVA) was used to compare all variables between groups. Two-way ANOVA with post hoc Tukey testing was used for multiple comparison purposes. A $p$-value of $<0.05$ was considered statistically significant.

\section{Results}

\section{Effect of exercise training on exercise tolerance and plasma norepinephrine levels}

After 8 weeks of moderate-intensity exercise training in sham-operated and $\mathrm{MI}$ mice, $\mathrm{MI}$ mice covered a shorter distance compared to sham-operated counterparts. Of note, exercise in $\mathrm{MI}$ mice not only suppressed the decrease in exercise tolerance, but also increased it towards exercise-trained sham-operated mice (Figure $1 \mathrm{~A}$ ).

Myocardial infarction mice displayed increased plasma norepinephrine levels compared with sham-operated mice. Exercise training significantly reduced plasma norepinephrine in $\mathrm{MI}$ mice toward untrained sham-operated levels (Figure 1 B).

\section{Effect of exercise training on hemodynamic status and LV systolic function}

MI mice displayed baseline tachycardia compared with sham-operated mice. Exercise training signifi- 
A

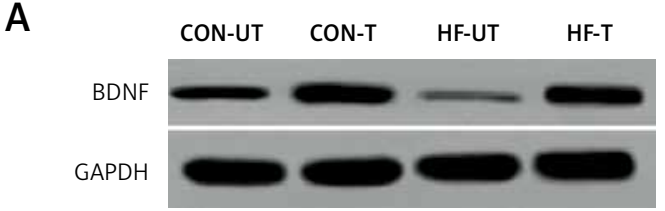

B

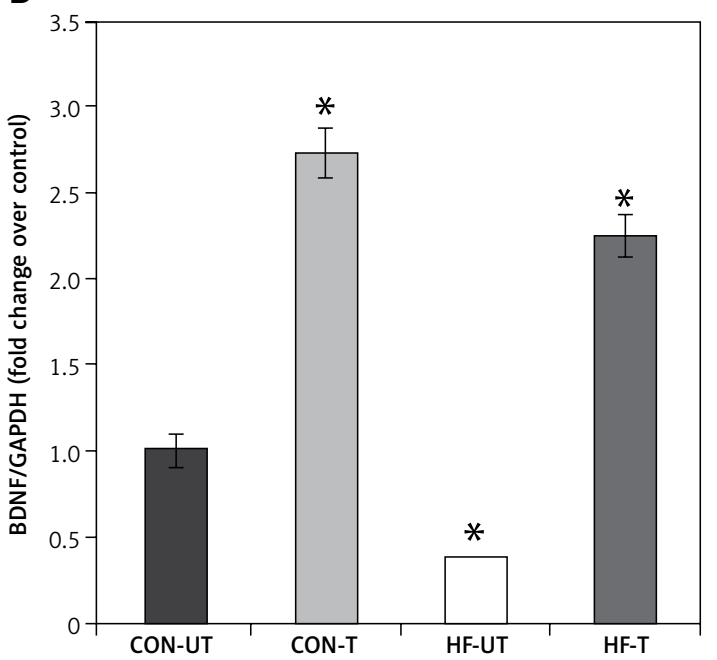

C

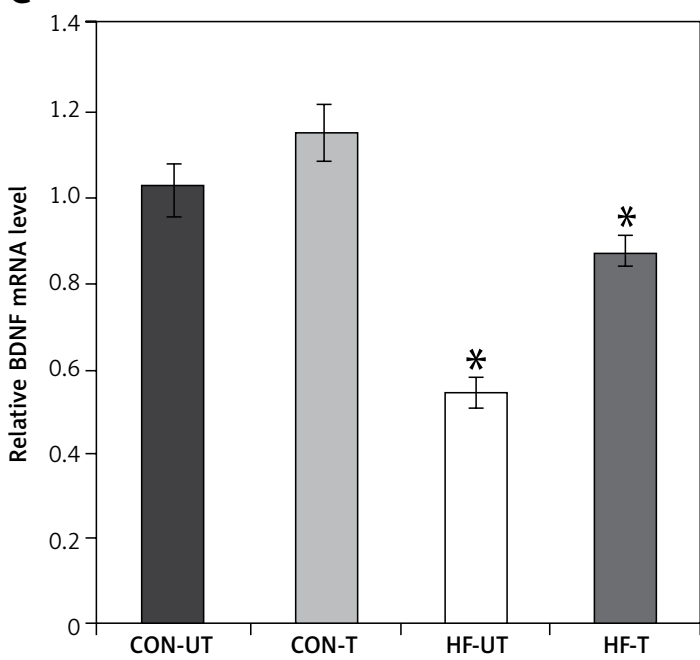

Figure 3. BDNF expression in untrained and exercise-trained sham-operated, and MI mice. A - Representative blots of BDNF from untrained (CONUT) and exercise-trained sham-operated (CON-T) and untrained (HF-UT) and trained MI (HF-T) mice. B - Relative protein band density values of BDNF were calculated as the ratio of the protein of interest to that of GAPDH. C - Relative mRNA expression of BDNF

Data are presented as means \pm SE. ${ }^{*} P<0.05$ vs. CON-UT group.

cantly reduced $\mathrm{HR}$ in both sham-operated and $\mathrm{MI}$ mice from the third week to the end of the 8-week training period. The reduction of HR in MI was so remarkable that it reached untrained sham-operated levels at the sixth week of training (Figure $2 \mathrm{~A}$ ).

Regarding echocardiographic evaluation, FS and EF were significantly decreased in the MI group compared with the sham-operated group. Eight weeks of exercise training tended to prevent the systolic dysfunction in MI mice (Figures $2 \mathrm{~B}, \mathrm{C}$ ).

\section{Effect of exercise training on BDNF expression}

It is well recognized that exercise has a significant impact on BDNF expression, which is involved in neuroplastic processes, contributing to recovery from ischemia [25]. Based on this evidence, we investigated mRNA and protein expression of BDNF in skeletal muscle from sham-operated and MI mice. BDNF mRNA and protein levels were significantly lower in the skeletal muscle from Ml compared to sham-operated mice (Figures $3 \mathrm{~A}-\mathrm{C}$ ). However, exercise training prevented the reduction of BDNF content in $\mathrm{MI}$ mice (Figures $3 \mathrm{~A}-\mathrm{C}$ ).

\section{Effect of exercise training on the components of signaling pathway downstream BDNF}

Phosphorylated protein TrkB and AMPK were reduced in the skeletal muscle from $M I$ mice, in association with the decreases in PGC1 $\alpha$ levels. Exercise training significantly increased phosphorylated TrkB, AMPK and PGC1 $\alpha$ levels in MI mice (Figures 4 A-D).

\section{Effect of BDNF inhibition during myogenic differentiation of $\mathrm{C} 2 \mathrm{C} 12$ cells}

To clarify the role of BDNF in the maintenance of exercise capacity, we examined the effects of its depletion in $\mathrm{C} 2 \mathrm{C} 12$ myoblasts. BDNF siRNA resulted in a markedly decreased level of phosphorylation of AMPK and PGC $1 \alpha$ proteins (Figure $5 \mathrm{~A}$ ). A control siRNA had no such effects. These results suggest that BDNF may regulate skeletal muscle function in HF mice after MI through AMPK-PGC1 $\alpha$ signaling.

\section{Discussion}

In the present study, we demonstrated for the first time that restoring the BDNF/TrkB and AMPK/ PGC $-1 \alpha$ signaling pathway is a crucial mechanism by which exercise training attenuates muscle dysfunction in HF. Our main finding was that exercise training significantly attenuated the reduction in the expression of BDNF, $p$-TrkB, p-AMPK and $P G C-1 \alpha$, restoring exercise tolerance.

A wealth of evidence has indicated that regular exercise can protect individuals from a host of cardiovascular and metabolic diseases $[3,26]$. Indeed, exercise training is emerging as a key intervention for preventive cardiology [27] and a nonpharmacological strategy for HF therapy [28]. Such 
A

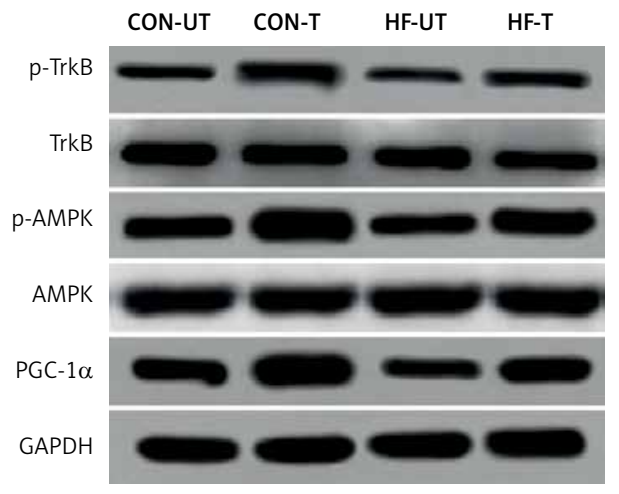

C

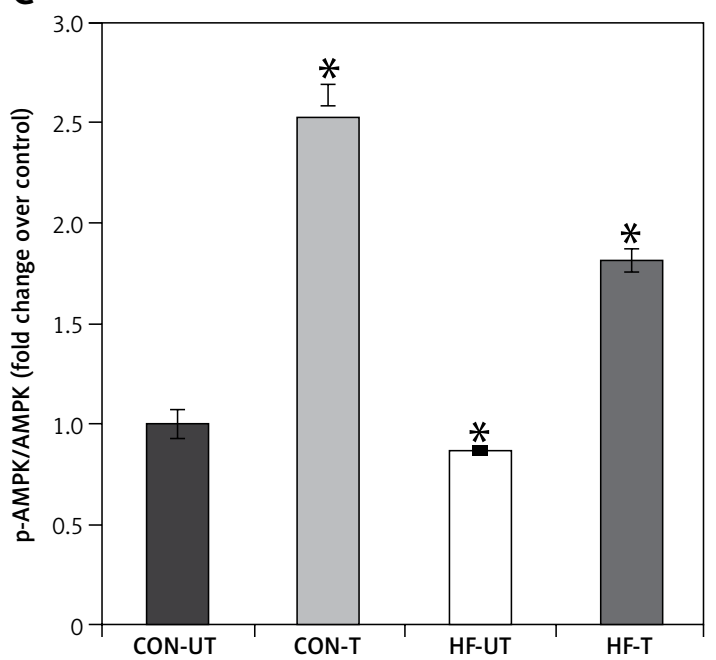

B

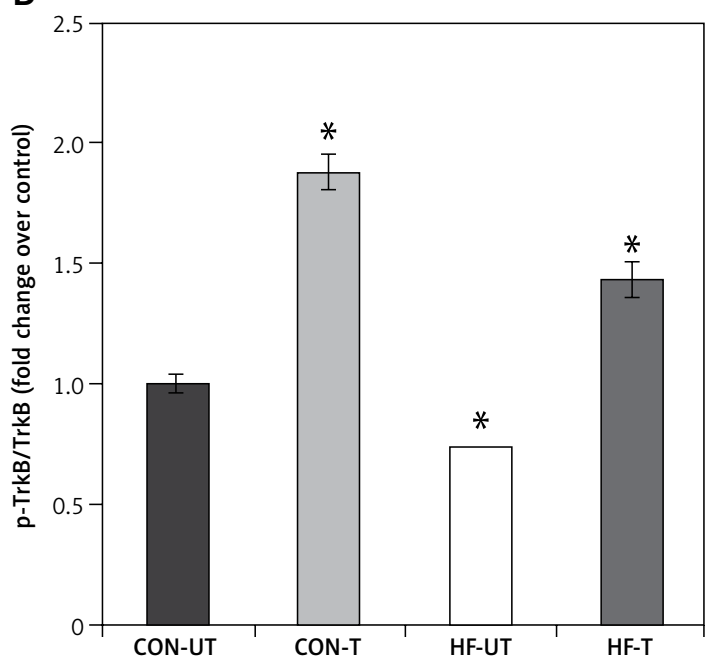

D

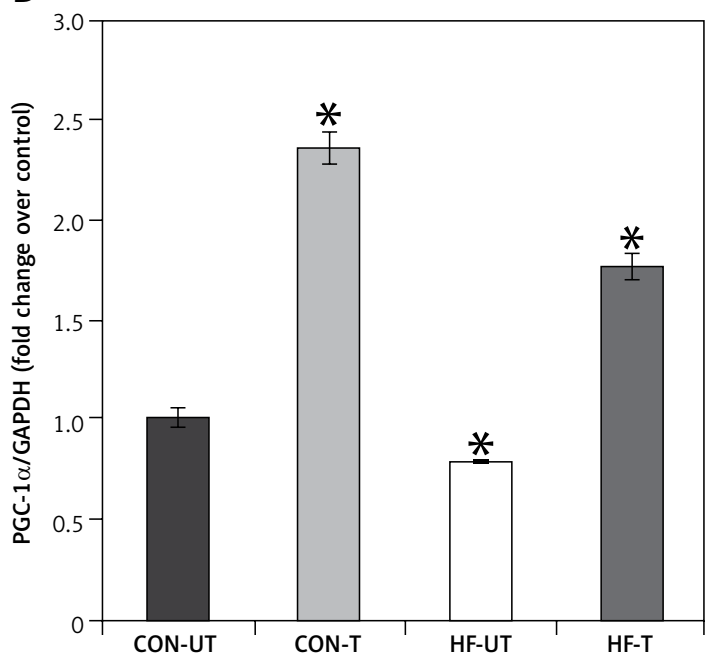

Figure 4. P-TrkB, $\mathrm{P}-\mathrm{AMPK}$ and PGC-1 $\alpha$ expression in untrained and exercise-trained sham-operated, and MI mice. A - Representative blots of p-TrkB, p-AMPK and PGC-1 $\alpha$ from untrained (CON-UT) and exercise-trained sham-operated (CON-T) and untrained (HF-UT) and trained MI (HF-T) mice. B-D - Relative protein band density values of p-TrkB, p-AMPK and PGC-1 $\alpha$ were calculated as the ratio of the protein of interest to that of GAPDH

Data are presented as means $\pm S E$. ${ }^{*} P<0.05$ vs. CON-UT group.

relevance is due to the ability of exercise training to counteract neurohumoral overactivity in $\mathrm{HF}$ $[24,29]$, which attenuates cardiac and skeletal muscle dysfunction [5,30], and ultimately leads to improved exercise tolerance and life quality in $\mathrm{HF}$ patients [31]. However, the mechanisms by which exercise training can prevent cardiovascular diseases are not completely understood. In the present investigation we demonstrate that exercise training in $\mathrm{Ml}$-induced $\mathrm{HF}$ mice increased BDNF, p-TrkB, p-AMPK and PGC- $1 \alpha$ levels, and prevented skeletal muscle atrophy and cardiac dysfunction.

BDNF plays a key role in neuron development, survival, and function, and seems to play a key role in mediating the benefits of exercise [32, 33]. BDNF is shown to be produced in the skeletal muscle, and increased by muscle contraction to enhance fat oxidation, which can regulate glucose and fat metabolism [34, 35]. The decrease in BDNF levels may be due to the physical inactivity in HF patients, and could impair the metabolism of skeletal muscle and lead to exercise intolerance $[36,37]$. Furthermore, BDNF levels in the skeletal muscle can be enhanced by exercise training [38, 39], and a beneficial effect of exercise training on HF might be due to BDNF release from the skeletal muscle. Lee et al. found that BDNF is induced by exercise training in skeletal muscle and the non-infarct area of the LV, which may contribute to improvement of muscle dysfunction and cardiac function after MI [40]. Exogenous BDNF increases evoked acetylcholine (ACh) release at the neuro- 
A

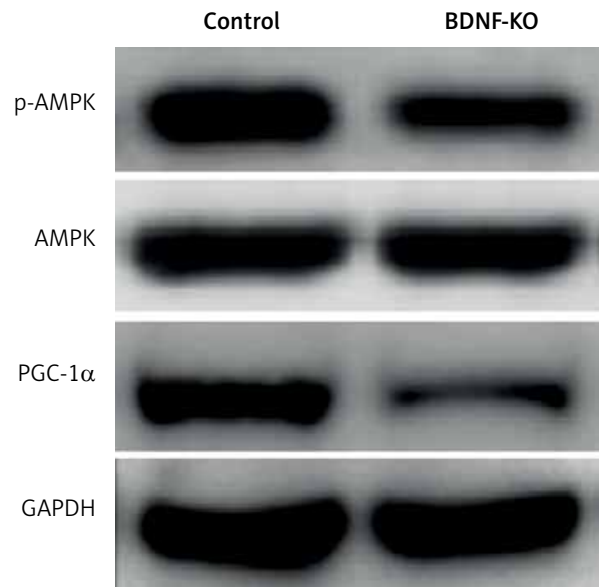

B

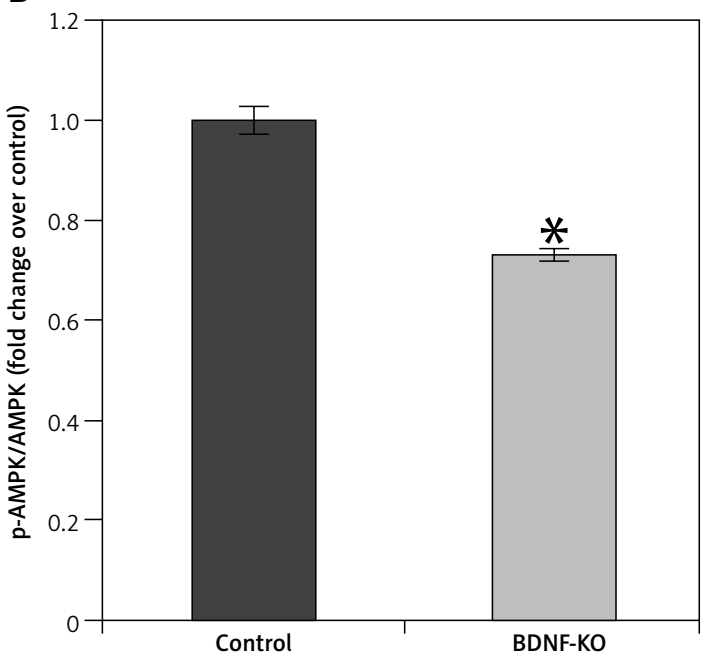

C

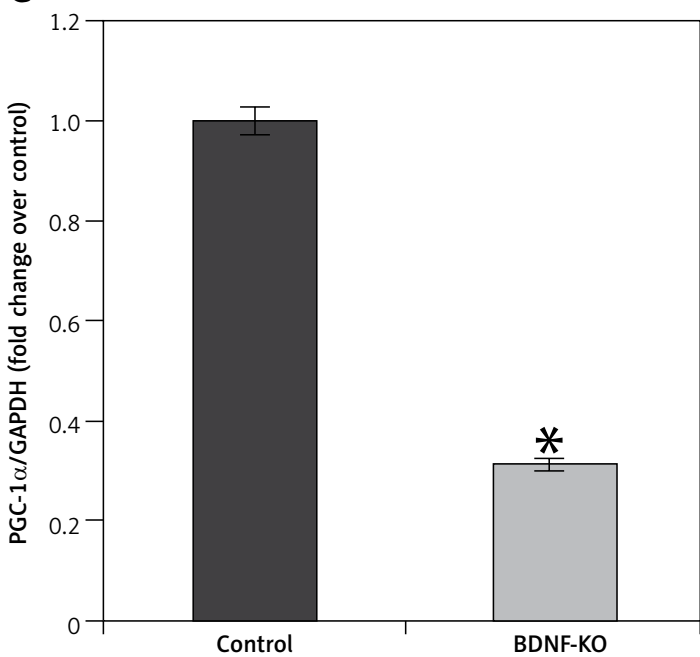

Figure 5. P-AMPK and PGC- $1 \alpha$ expression in un treated and BDNF siRNA treated $\mathrm{C} 2 \mathrm{C} 12$ myoblasts. A - Representative blots of $p-A M P K$ and PGC- $1 \alpha$. B, C - Relative protein band density values of p-AMPK and PGC- $1 \alpha$ were calculated as the ratio of protein of interest to that of GAPDH

Data are presented as means $\pm S E .{ }^{\star} P<0.05$ vs. Control group. muscular junction (NMJ) and the TrkB receptor is normally coupled to this process $[41,42]$. These results suggest that BDNF may play a critical role in metabolic derangements [35]. Further studies are needed to better understand the pathophysiology underlying the relationship between BDNF levels in skeletal muscle and exercise intolerance in HF. Our data reinforce the reduction in BDNF and $\mathrm{p}$-TrkB protein levels in skeletal muscle of $\mathrm{HF}$ mice. Here we report that the mechanisms underlying the restoration in exercise tolerance and amelioration in ventricular function include the prevention of metabolism abnormalities by changing the BDNF level and phosphorylation status of TrkB proteins.

Peroxisome proliferator-activated receptor $\gamma$ coactivator- $1 \alpha(\mathrm{PGC}-1 \alpha)$ is a powerful stimulator of mitochondrial biogenesis and gene transcription in the skeletal muscle [19]. AMP-activated protein kinase (AMPK) is an upstream regulator for PGC-1 $\alpha$ [43], mediating PGC-1 $\alpha$ transcriptional activation in response to various stimuli [44]. Regarding downstream BDNF/p-TrkB signaling pathway, we observed that exercise training increased PGC-1 $\alpha$ expression levels and re-established AMPK phosphorylation levels in HF mice. Increased p-AMPK and PGC-1 $\alpha$ levels suggest a major role of AMPK/PGC-1 $\alpha$ in the anabolic effect of exercise training when muscle dysfunction is taking place. This is an important result, highlighting the homeostatic role of exercise training in counteracting muscle dysfunction rather than increasing AMPK/ PGC-1 $\alpha$ signaling that is known to be activated by exercise training in eutrophic conditions [45].

These results suggest that the mechanism underlying exercise-induced cardioprotection and maintenance of exercise capacity may be influenced by factors such as training regimen and $\mathrm{HF}$ etiology. Our study shows that in a model of $M I$ induced $\mathrm{HF}$, exercise training restored BDNF, $p$-TrkB, p-AMPK and PGC-1 $\alpha$ expression to control levels. One may consider that exercise training favors mitochondrial biogenesis by AMPK/PGC-1 $\alpha$, preventing the impairment of metabolism by BDNF. Herein, we demonstrated that improved muscle function is associated, at least in part, with a reestablished BDNF/TrkB and AMPK/PGC-1 $\alpha$ signaling pathway.

In conclusion, our findings provide strong evidence for the contribution of BDNF to exercise training maintaining exercise capacity and regulating cardiac function in $\mathrm{HF}$ mice after MI through AMPK-PGC- $1 \alpha$ signaling. Altogether, these findings strengthen exercise training as an efficient therapeutic approach in HF. Future studies should investigate the ideal exercise intensity and duration in order to optimize both muscle anti-atrophic effects of exercise training in HF. 


\section{Acknowledgments}

Zheng Zhang and Beili Wang contributed equally to the study.

\section{Conflict of interest}

The authors declare no conflict of interest.

\section{References}

1. Emter CA, McCune SA, Sparagna GC, Radin MJ, Moore RL. Low-intensity exercise training delays onset of decompensated heart failure in spontaneously hypertensive heart failure rats. Am J Physiol Heart Circ Physiol 2005; 289: H2030-8.

2. Powers S, Lennon SL, Quindry J, Mehta JL. Exercise and cardioprotection. Curr Opin Cardiol 2002; 17: 495-502.

3. Fang J, Wylie-Rosett J, Cohen HW, Kaplan RC, Alderman $\mathrm{MH}$. Exercise, body mass index, caloric intake, and cardiovascular mortality. Am J Prev Med 2003; 25: 283-9.

4. Sigal RJ, Kenny GP, Wasserman DH, Castaneda-Sceppa C, White RD. Physical activity/exercise and type 2 diabetes. Diabetes Care 2006; 29: 1433-8.

5. Crimi E, Ignarro LJ, Cacciatore F, Napoli C. Mechanisms by which exercise training benefits patients with heart failure. Nat Rev Cardiol 2009; 6: 292-300.

6. Lunde PK, Sjaastad I, Schiøtz Thorud HM, Sejersted OM. Skeletal muscle disorders in heart failure. Acta Physiol 2001; 171: 277-94.

7. Mancini DM, Eisen H, Kussmaul W, Mull R, Edmunds LH Jr, Wilson JR. Value of peak exercise oxygen consumption for optimal timing of cardiac transplantation in ambulatory patients with heart failure. Circulation 1991; 83: 778-86.

8. Keteyian SJ, Levine AB, Brawner CA, et al. Exercise training in patients with heart failure a randomized, controlled trial. Ann Intern Med 1996; 124: 1051-7.

9. Maiorana A, O'Driscoll G, Cheetham C, et al. Combined aerobic and resistance exercise training improves functional capacity and strength in CHF. J Appl Physiol 2000; 88: 1565-70.

10. Jónsdóttir S, Andersen KK, Sigurosson AF, Sigurosson SB. The effect of physical training in chronic heart failure. Eur J Heart Failure 2006; 8: 97-101.

11. Mattson MP, Maudsley S, Martin B. BDNF and 5-HT: a dynamic duo in age-related neuronal plasticity and neurodegenerative disorders. Trends Neurosci 2004; 27: 589-94.

12. Donovan MJ, Lin MI, Wiegn P, et al. Brain derived neurotrophic factor is an endothelial cell survival factor required for intramyocardial vessel stabilization. Development 2000; 127: 4531-40.

13. Yang B, Slonimsky JD, Birren SJ. A rapid switch in sympathetic neurotransmitter release properties mediated by the p75 receptor. Nat Neurosci 2002; 5: 539-45.

14. Kermani P, Hempstead B. Brain-derived neurotrophic factor: a newly described mediator of angiogenesis. Trends Cardiovasc Med 2007; 17: 140-3.

15. Okada S, Yokoyama M, Toko H, et al. Brain-derived neurotrophic factor protects against cardiac dysfunction after myocardial infarction via a central nervous system-mediated pathway. Arterioscler Thromb Vasc Biol 2012; 32: 1902-9.

16. Becker BK, Tian C, Zucker IH, Wang HJ. Influence of brain-derived neurotrophic factor-tyrosine receptor kinase $B$ signalling in the nucleus tractus solitarius on baroreflex sensitivity in rats with chronic heart failure. J Physiol 2016; 594: 5711-25.

17. Ferris LT, Williams JS, Shen CL. The effect of acute exercise on serum brain-derived neurotrophic factor levels and cognitive function. Med Sci Sports Exerc 2007; 39: 728-34.

18. Gao Q, Wang G, Wang F, Zhang W, Qing H. Effects of a long term physical exercise on the MRNA level of BDNF in mice after middle cerebral artery occlusion. Int J Neurorehabil 2015; 2: 3.

19. Handschin C, Spiegelman BM. Peroxisome proliferatoractivated receptor gamma coactivator 1 coactivators, energy homeostasis, and metabolism. Endocr Rev 2006; 27: 728-35.

20. Michael LH, Entman ML, Hartley CJ, et al. Myocardial ischemia and reperfusion: a murine model. Am J Physiol Heart Circ Physiol 1995; 269: H2147-54.

21. Evangelista F, Brum P, Krieger J. Duration-controlled swimming exercise training induces cardiac hypertrophy in mice. Braz J Med Biol Res 2003; 36: 1751-9.

22. Ferreira JC, Rolim NP, Bartholomeu JB, Gobatto CA, Kokubun E, Brum PC. Maximal lactate steady state in running mice: effect of exercise training. Clin Exp Pharmacol Physiol 2007; 34: 760-5.

23. Wu J, Bu L, Gong H, et al. Effects of heart rate and anesthetic timing on high-resolution echocardiographic assessment under isoflurane anesthesia in mice. J Ultrasound Med 2010; 29: 1771-8.

24. Medeiros A, Rolim NP, Oliveira RS, et al. Exercise training delays cardiac dysfunction and prevents calcium handling abnormalities in sympathetic hyperactivity-induced heart failure mice. J Appl Physiol 2008; 104: 103-9.

25. Szuhany KL, Bugatti M, Otto MW. A meta-analytic review of the effects of exercise on brain-derived neurotrophic factor. J Psychiatr Res 2015; 60: 56-64.

26. Kannel W, Wilson P, Blair S. Epidemiological assessment of the role of physical activity and fitness in development of cardiovascular disease. Am Heart J 1985; 109: 876-85.

27. Freimann S, Scheinowitz M, Yekutieli D, Feinberg MS, Eldar M, Kessler-Icekson G. Prior exercise training improves the outcome of acute myocardial infarction in the rat: heart structure, function, and gene expression. J Am Coll Cardiol 2005; 45: 931-8.

28. Brum P, Bacurau AVN, Medeiros A, Ferreira JCB, Vanzelli AS, Negrão CE. Aerobic exercise training in heart failure: impact on sympathetic hyperactivity and cardiac and skeletal muscle function. Braz J Med Biol Res 2011; 44: 827-35.

29. Bacurau AV, Jannig PR, de Moraes WM, et al. Akt/mTOR pathway contributes to skeletal muscle anti-atrophic effect of aerobic exercise training in heart failure mice. Int J Cardiol 2016; 214: 137-47.

30. Cunha TF, Bacurau AVN, Moreira JBN, et al. Exercise training prevents oxidative stress and ubiquitin-proteasome system overactivity and reverse skeletal muscle atrophy in heart failure. PloS One 2012; 7: e41701.

31. Piepoli MF, Conraads V, Corrà U, et al. Exercise training in heart failure: from theory to practice. A consensus document of the Heart Failure Association and the European Association for Cardiovascular Prevention and Rehabilitation. Eur J Heart Failure 2011; 13: 347-57.

32. Ghosh A, Carnahan J, Greenberg ME. Requirement for BDNF in activity-dependent survival of cortical neurons. Science 1994; 263: 1618-24.

33. Gomez-Pinilla F, Hillman C. The influence of exercise on cognitive abilities. Compr Physiol 2013; 3: 403-28. 
34. Matthews V, Aström MB, Chan MH, et al. Brain-derived neurotrophic factor is produced by skeletal muscle cells in response to contraction and enhances fat oxidation via activation of AMP-activated protein kinase. Diabetologia 2009; 52: 1409-18.

35. Pedersen BK, Pedersen M, Krabbe KS, Bruunsgaard $H$, Matthews VB, Febbraio MA. Role of exercise-induced brain-derived neurotrophic factor production in the regulation of energy homeostasis in mammals. Exp Physiol 2009; 94: 1153-60.

36. Fukushima A, Kinugawa S, Homma T, et al. Decreased serum brain-derived neurotrophic factor levels are correlated with exercise intolerance in patients with heart failure. Int J Cardiol 2013; 168: e142-4.

37. Takashio S, Sugiyama S, Yamamuro M, et al. Significance of low plasma levels of brain-derived neurotrophic factor in patients with heart failure. Am J Cardiol 2015; 116: 243-9.

38. Pedersen BK, Febbraio MA. Muscles, exercise and obesity: skeletal muscle as a secretory organ. Nat Rev Endocrinol 2012; 8: 457-65.

39. Ogborn DI, Gardiner PF. Effects of exercise and muscle type on BDNF, NT-4/5, and TrKB expression in skeletal muscle. Muscle Nerve 2010; 41: 385-91.

40. Lee HW, Ahmad M, Wang HW, Leenen FH. Effects of exercise training on brain-derived neurotrophic factor in skeletal muscle and heart of rats post myocardial infarction. Exp Physiol 2017; 102: 314-28.

41. Santafé MM, Garcia N, Tomàs $M$, et al. The interaction between tropomyosin-related kinase $\mathrm{B}$ receptors and serine kinases modulates acetylcholine release in adult neuromuscular junctions. Neurosci Letters 2014; 561: 171-5.

42. Hurtado E, Cilleros V, Nadal L, et al. Muscle contraction regulates $B D N F / T r k B$ signaling to modulate synaptic function through presynaptic CPKCalpha and CPKCbetal. Front Mol Neurosci 2017; 10: 147.

43. Colombo SL, Moncada S. AMPKalpha1 regulates the antioxidant status of vascular endothelial cells. Biochem J 2009; 421: 163-9.

44. Li L, Xiao L, Hou Y, et al. Sestrin2 silencing exacerbates cerebral ischemia/reperfusion injury by decreasing $\mathrm{mi}$ tochondrial biogenesis through the AMPK/PGC-1alpha pathway in rats. Sci Rep 2016; 6: 30272.

45. Egan B, Zierath JR. Exercise metabolism and the molecular regulation of skeletal muscle adaptation. Cell Metabol 2013; 17: 162-84. 